\title{
Raman Spectroscopy for Understanding of Lithium Intercalation into Graphite in Propylene Carbonated-Based Solutions
}

\author{
Yang-Soo Kim ${ }^{1}$ and Soon-Ki Jeong ${ }^{2}$ \\ ${ }^{1}$ Korea Basic Science Institute, Suncheon Center, Suncheon 540-742, Republic of Korea \\ ${ }^{2}$ Department of Chemical Engineering, Soonchunhyang University, Asan, Chungnam 336-745, Republic of Korea \\ Correspondence should be addressed to Soon-Ki Jeong; hamin611@sch.ac.kr
}

Received 22 August 2014; Accepted 2 October 2014

Academic Editor: Tifeng Jiao

Copyright (c) 2015 Y.-S. Kim and S.-K. Jeong. This is an open access article distributed under the Creative Commons Attribution License, which permits unrestricted use, distribution, and reproduction in any medium, provided the original work is properly cited.

\begin{abstract}
Electrochemical lithium intercalation within graphite was investigated in propylene carbonate (PC) containing different concentrations, $0.4,0.9,1.2,2.2,2.8,3.8$, and $4.7 \mathrm{~mol} \mathrm{dm}^{-3}$, of lithium perchlorate, $\mathrm{LiClO}_{4}$. Lithium ion was reversibly intercalated into and deintercalated from graphite in 3.8 and $4.7 \mathrm{~mol} \mathrm{dm}^{-3}$ solutions despite the use of pure PC as the solvent. However, ceaseless solvent decomposition and intense exfoliation of the graphene layers occurred in other solutions. The results of the Raman spectroscopic analysis indicated that contact ion pairs are present in 3.8 and $4.7 \mathrm{~mol} \mathrm{dm}^{-3}$ solutions, which suggested that the presence of contact ion pairs is an important factor that determines the solid electrolyte interphase- (SEI-) forming ability in PC-based electrolytes.
\end{abstract}

\section{Introduction}

In commercially available lithium secondary batteries, lithium ions are electrochemically intercalated into and deintercalated from the graphite negative electrode during charging and discharging, respectively. These electrochemical reactions are basically reversible; however, the reversibility depends greatly on the kind of electrolyte solutions. They are highly reversible in ethylene carbonate- (EC-) based solutions containing lithium salts such as $\mathrm{LiClO}_{4}, \mathrm{LiPF}_{6}$, and $\mathrm{LiCF}_{3} \mathrm{SO}_{3}$. The discovery of EC-based electrolyte systems is a seminal breakthrough that has enabled the electrochemical preparation of lithium-graphite intercalation compounds (Li-GICs) [1,2]. On the other hand, propylene carbonate (PC)-based solutions are attractive electrolyte systems owing to their superior ionic conductivities when compared to EC-based solutions at low temperatures [3]. However, it is very difficult to get Li-GICs in PC-based electrolytes because of poor compatibility between graphite and PC [4-6].

In a previous study [7], we reported a simple electrochemical preparation of Li-GICs in PC-based solutions, $\mathrm{LiN}\left(\mathrm{SO}_{2} \mathrm{C}_{2} \mathrm{~F}_{5}\right)_{2}$ (LiBETI) dissolved in PC. The work showed that lithium intercalation within graphite from the LiBETIPC solutions is an electrochemical reaction that strongly depends on the electrolyte concentration. Lithium ions were intercalated within graphite to form a stage $1 \mathrm{Li}-\mathrm{GIC}$ in concentrated LiBETI-PC solutions whereas solvent decomposition or the intensive exfoliation of graphene layers occurred continuously in relatively low-concentration solutions; that is, the poor compatibility between graphite and PC could be improved by increasing electrolyte concentration. However, the details for the effects of electrolyte concentration on lithium intercalation and deintercalation reactions are still unclear. In this study, we performed Raman spectroscopic analysis to know the correlations between electrolyte concentration and interfacial reactions between graphite and PCbased solutions.

\section{Experimental}

The electrolyte solutions were prepared by dissolving $\mathrm{LiClO}_{4}$ in PC. All these reagents were purchased from Kishida Chemical Co. and were used as received. The concentrations of $\mathrm{LiClO}_{4}$ were $0.4,0.9,1.2,2.2,2.8,3.8$, and $4.7 \mathrm{~mol} \mathrm{dm}^{-3}$, which correspond to $20: 1,1: 9,1: 7,1: 5,1: 4,1: 3$, and $1: 2$, respectively, by the molar ratio of $\mathrm{Li}^{+}$to $\mathrm{PC}$. The water content in each solution was less than $30 \mathrm{ppm}$, which was confirmed using a Karl-Fischer moisture titrator (Kyoto Electronics 
Manufacturing Co., MKC-210). The concentration of all electrolyte solutions is expressed as the molarity of lithium salt $\left(\mathrm{mol} \mathrm{dm}^{-3}\right)$.

Natural graphite powder (The Kansai Coke and Chemicals Co., NG-7) was used for the charge/discharge tests. The test electrode was prepared by coating a mixture of the graphite powder (90 wt\%) and a polymeric binder (10 wt $\%)$ on copper foil, as described elsewhere [8]. The charge and discharge tests were carried out using conventional threeelectrode cells at a constant current of $5.2 \mathrm{~mA} \mathrm{~g}^{-1}$ in an argonfilled glove-box (Miwa, MDB-1B+MM3-P60S) with a dew point below $-60^{\circ} \mathrm{C}$. Lithium foil was used as the counter and reference electrodes. All potentials are referred to as volts versus $\mathrm{Li}^{+} / \mathrm{Li}$.

Raman spectra of the electrolyte solutions were recorded using a triple monochromator (Jobin-Yvon, T-64000). Excitation was carried out with a $514.5 \mathrm{~nm}$ line $(50 \mathrm{~mW})$ from an argon ion laser (NEC, GLG2265). The scattered light was collected in a direction of $90^{\circ}$ to the incident light.

\section{Results and Discussion}

In a previous study [7], we used LiBETI-PC solutions of different concentrations as electrolytes, as mentioned in the introduction, to investigate the effects of electrolyte concentration on lithium intercalation into graphite. In the present study, however, $\mathrm{LiClO}_{4}$-PC solutions instead of LiBETI-PC solutions were used as electrolytes because a lot more information on ion-solvent or ion-ion interactions which would be expected to have an effect on interfacial reactions between electrode and electrolyte can be obtained from the former solution by Raman spectroscopy. Before the Raman spectroscopic analysis, the charging (lithium intercalation) and discharging (lithium deintercalation) of the graphite electrode was executed in seven $\mathrm{LiClO}_{4}$-PC electrolytes of different concentrations: $0.4,0.9,1.2,2.2,2.8,3.8$, and $4.7 \mathrm{~mol} \mathrm{dm}^{-3}$. The graphite electrode showed electrolyte concentration dependence of the electrochemical lithium intercalation reaction in $\mathrm{LiClO}_{4}-\mathrm{PC}$ solutions similar to that observed in LiBETI-PC solutions. Among the electrolytes, the 3.8 and $4.7 \mathrm{~mol} \mathrm{dm}^{-3}$ solutions were effective for the electrochemical preparation of Li-GICs. No lithium intercalation and deintercalation reactions occurred in the other solutions.

The potential profiles of natural graphite powder during the first charging and discharging cycles in 2.8 and $3.8 \mathrm{~mol} \mathrm{dm}^{-3}$ solutions are shown in Figure 1 (potential profiles obtained in the other solutions are not shown here). It is well known that the electrochemical intercalation of lithium into graphite mainly occurs at potentials below $0.25 \mathrm{~V}$ [9-11]. There was no charge capacity at the potential profile obtained in $2.8 \mathrm{~mol} \mathrm{dm}^{-3}$ solution. In contrast, the charge capacity corresponding to lithium intercalation was recorded at potentials below $0.25 \mathrm{~V}$ in $3.8 \mathrm{~mol} \mathrm{dm}^{-3}$ solution. Potential plateaus observed at $0.170,0.080$, and $0.045 \mathrm{~V}$ during charging and $0.135,0.180$, and $0.255 \mathrm{~V}$ during discharging in Figure 1(b) are direct evidence of lithium intercalation and deintercalation. The potential plateaus can be assigned to reversible stage transformations between Li-GICs of different stage numbers.

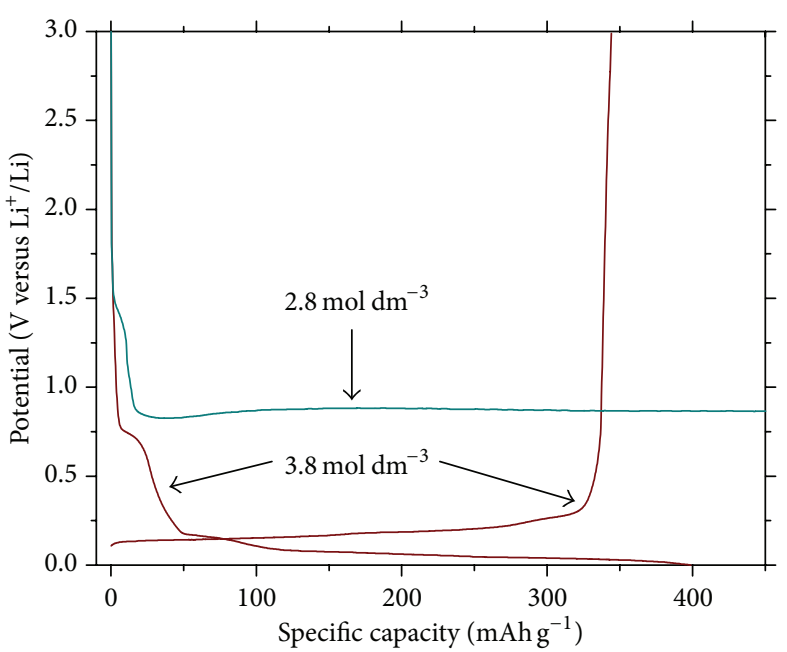

(a)

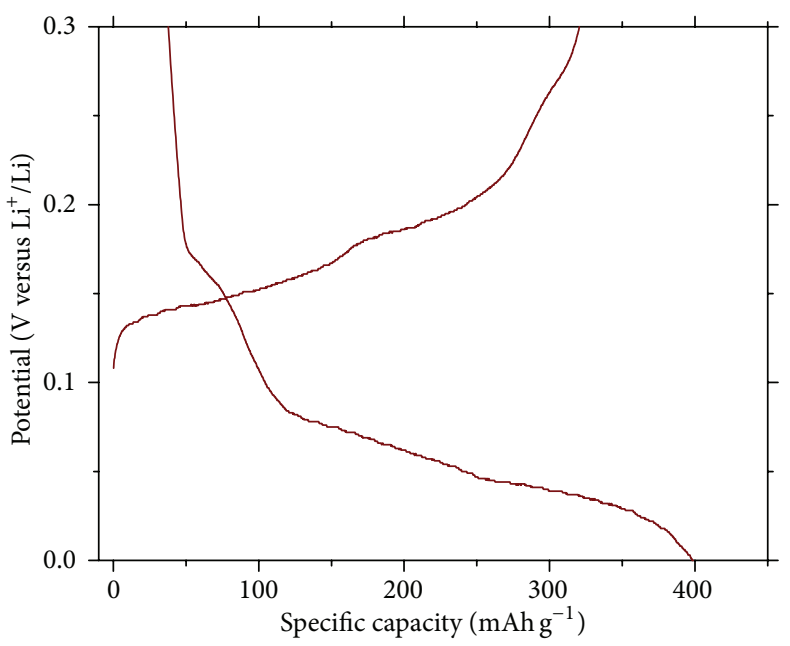

(b)

FIGURE 1: (a) Charge and discharge curves in the first cycle of natural graphite powder (NG-7) in 2.8 and $3.8 \mathrm{~mol} \mathrm{dm}^{-3} \mathrm{LiClO}_{4}$ dissolved in PC. (b) Magnified view of panel (a).

The above results demonstrate that the solid electrolyte interphase- (SEI-) forming ability of $\mathrm{LiClO}_{4}$-PC electrolytes is greatly dependent on the concentration of $\mathrm{LiClO}_{4}$. The following two possibilities can be considered as the reason for SEI formation on graphite surface to form Li-GICs in high-concentration solutions. First, it may be due to the structural changes in solvated lithium ions as the concentration increases, because the electrolyte decomposition and exfoliation of graphene layers at around $0.8 \mathrm{~V}$ in the $2.8 \mathrm{~mol} \mathrm{dm}^{-3}$ solution are originated from the intercalation of solvated lithium ions [12]. The structural changes may lower the potential of solvated lithium ions to be intercalated into graphite, resulting in forming an SEI by the decomposition of electrolyte below $0.8 \mathrm{~V}$. Second, a new chemical species may have been produced in high-concentration solutions, resulting in their decomposition to form an SEI.

The ion-solvent interactions between lithium ions and PC molecules were investigated by laser Raman spectroscopy 
TABLE 1: Mole fraction of solvated PC molecules and chargedischarge behaviors of graphite in $\mathrm{LiClO}_{4}-\mathrm{PC}$ solutions.

\begin{tabular}{lcc}
\hline $\begin{array}{l}\text { Concentration } \\
\left(\mathrm{mol} \mathrm{dm}^{-3}\right)\end{array}$ & Charging-discharging & $\begin{array}{c}\text { Mole fraction of } \\
\text { solvated PC }\end{array}$ \\
\hline 4.7 & Success & 0.91 \\
3.8 & Success & 0.82 \\
2.8 & Failure & 0.63 \\
2.2 & Failure & 0.52 \\
1.2 & Failure & 0.36 \\
0.9 & Failure & 0.26 \\
0.4 & Failure & 0.05 \\
\hline
\end{tabular}

to confirm the first possibility. Figure 2 shows the Raman spectra of pure PC and $\mathrm{LiClO}_{4}$-PC solutions of different concentrations in the wavenumber range of 660 to $800 \mathrm{~cm}^{-1}$. The vibrational spectroscopy of PC in this frequency region provides useful information on the interactions between lithium ions and PC molecules [13-17]. In pure PC, the strong band at $712 \mathrm{~cm}^{-1}$ is assigned to the symmetric ring deformation mode of free PC molecules [13]. The shape of this band became less symmetric and a new band appeared at around $723 \mathrm{~cm}^{-1}$. The intensity of the new band increased with an increase in the concentration of $\mathrm{LiClO}_{4}$ whereas the intensity of the band from free PC decreased. This indicates that the new band is originated from the interaction between PC molecules and lithium ions and is assigned to the symmetric ring deformation mode of solvated PC [13-15]. The band from free PC almost disappeared in 3.8 and $4.7 \mathrm{~mol} \mathrm{dm}^{-3}$ solutions, indicating that most of PC molecules solvate lithium ions in the solutions. The mole fraction of the solvated PC molecules in each solution was obtained from the integrated intensities of the free or solvated PC bands (Table 1). Curve fitting was performed to separate each band. The 82 and $91 \%$ of PC molecules were solvated to lithium ions in 3.8 and $4.7 \mathrm{~mol} \mathrm{dm}^{-3}$ solutions, respectively, where an effective SEI was formed on graphite.

Figure 2 and Table 1 clearly show that there are structural changes in solvated lithium ions as the concentration changes. The solvation number of lithium ions in $\mathrm{LiClO}_{4}{ }^{-}$ $\mathrm{PC}$ solution is expected to decrease with an increase in the concentration of the lithium salt. Such a difference in the solvation number may result in suppressing the intercalation of solvated lithium ions and their decomposition occurring at around $0.8 \mathrm{~V}$ in the $2.8 \mathrm{~mol} \mathrm{dm}^{-3}$ solution or the solvated lithium ions may be intercalated at lower potentials than $0.8 \mathrm{~V}$, resulting in forming an SEI by the decomposition of electrolyte below $0.8 \mathrm{~V}$. If this assumption is correct, an SEI may be generated when the electrode potential is forced to step to a lower potential than $0.8 \mathrm{~V}$ in a short time. This is because the intercalation of solvated lithium ions is suppressed by the formation of an SEI although the two reactions are competing at the low potential. However, such an effective SEI was not formed, as shown in Figure 3.

Figure 3 shows chronoamperograms obtained after potential step from 2.9 to $0.3 \mathrm{~V}$ in 2.8 and $3.8 \mathrm{~mol} \mathrm{dm}^{-3}$

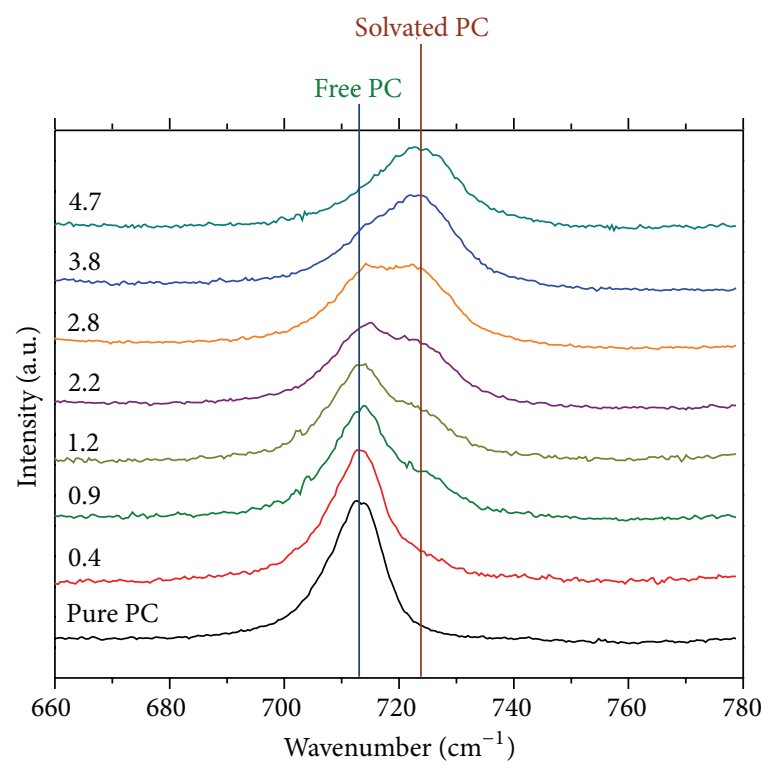

Figure 2: Raman spectra of pure PC and $\mathrm{LiClO}_{4}$-PC solutions of different concentrations. The concentration of all solutions is expressed as the molality of $\mathrm{LiClO}_{4}\left(\mathrm{~mol} \mathrm{dm}^{-3}\right)$ inside figure.

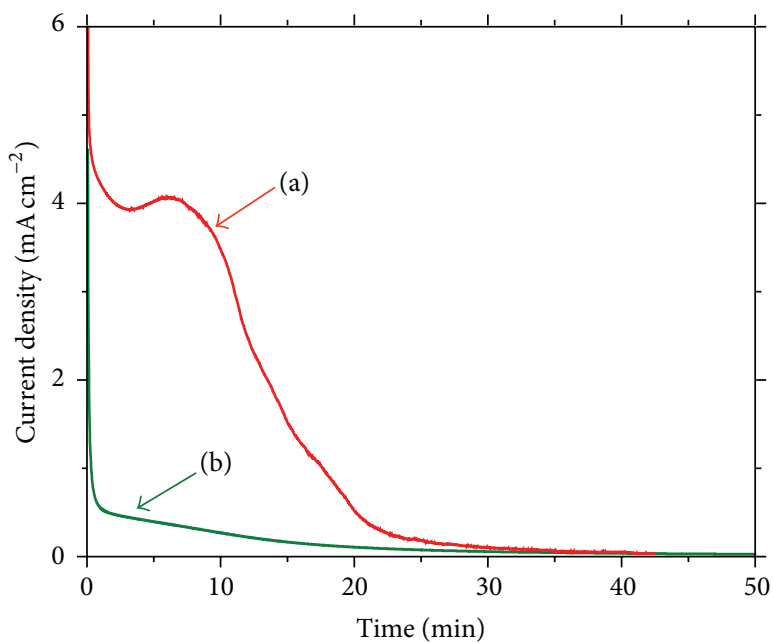

FIGURE 3: Current-time curves of the natural graphite powder (NG7) observed in response to the potential step from 2.9 to $0.3 \mathrm{~V}$ in (a) 2.8 and (b) $3.8 \mathrm{~mol} \mathrm{dm}^{-3} \mathrm{LiClO}_{4}$ dissolved in PC.

solutions. In $2.8 \mathrm{~mol} \mathrm{dm}^{-3}$ solution, more than 10 times more charge was consumed compared to that consumed in $3.8 \mathrm{~mol} \mathrm{dm}^{-3}$ solution, and exfoliation of graphene layers was also observed. This indicates that no SEI is formed on graphite by the decomposition of $2.8 \mathrm{~mol} \mathrm{dm}^{-3}$ solution. The above results demonstrate that a chemical species with the ability to generate an effective SEI is present in $3.8 \mathrm{~mol} \mathrm{dm}^{-3}$ solution, but not present in $2.8 \mathrm{~mol} \mathrm{dm}^{-3}$ solution. This, as mentioned earlier, supports the second possibility.

We noted that ion pairs are formed only in concentrated solutions and investigated them by laser Raman spectroscopy. Figure 4 shows the Raman spectra of pure PC and $\mathrm{LiClO}_{4}$ PC solutions of different concentrations in the wavenumber 
TABLE 2: Mole fraction of $\mathrm{ClO}_{4}{ }^{-}$anions and charge-discharge behaviors of graphite in $\mathrm{LiClO}_{4}-\mathrm{PC}$ solutions.

\begin{tabular}{llcc}
\hline Concentration $\left(\mathrm{mol} \mathrm{dm}^{-3}\right)$ & Charging-discharging & Mole fraction \\
Solvent-separated & 0.58 \\
Contact
\end{tabular}

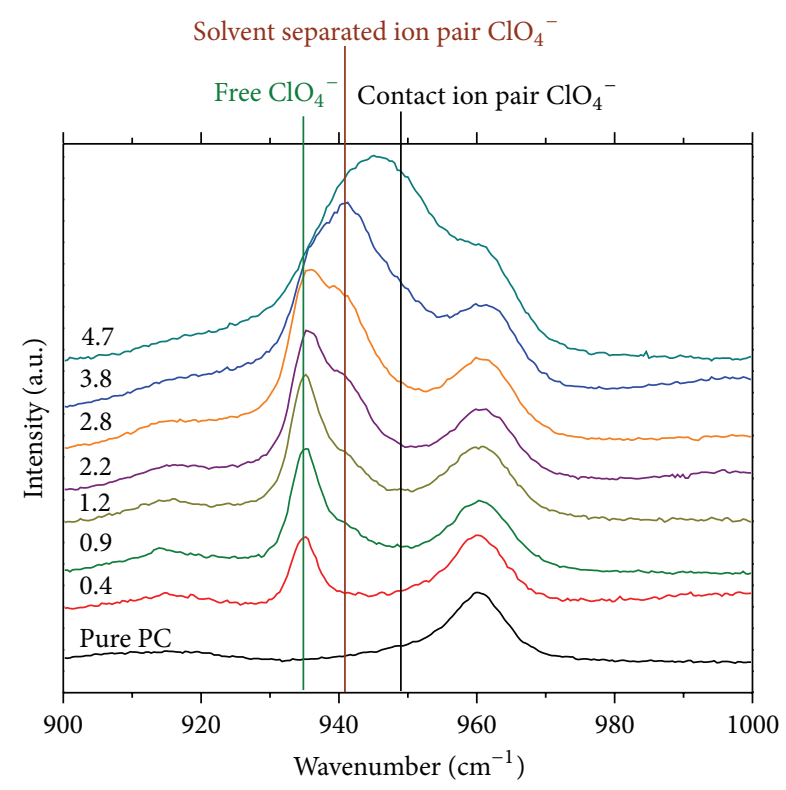

Figure 4: Raman spectra of pure PC and $\mathrm{LiClO}_{4}$-PC solutions of different concentrations. The concentration of all solutions is expressed as the molality of $\mathrm{LiClO}_{4}\left(\mathrm{~mol} \mathrm{dm}^{-3}\right)$ inside figure.

range of 900 to $1000 \mathrm{~cm}^{-1}$. The vibrational spectroscopy of $\mathrm{ClO}_{4}{ }^{-}$anions in this frequency region provides useful information on ion pairs. James et al. studied ion-ionsolvent interactions in $\mathrm{LiClO}_{4}$-acetone solutions with Raman spectroscopy [18]. They reported that there are four kinds of the symmetrical stretching vibration of $\mathrm{ClO}_{4}{ }^{-}$anions in solutions originating from (i) free anions, $\mathrm{ClO}_{4}{ }^{-}\left(934 \mathrm{~cm}^{-1}\right)$, (ii) solvent-separated ion pairs, $\mathrm{Li}^{+}$-solvent- $\mathrm{ClO}_{4}{ }^{-}\left(939 \mathrm{~cm}^{-1}\right)$, (iii) contact ion pairs, $\left[\mathrm{Li}^{+} \mathrm{ClO}_{4}^{-}\right]\left(948 \mathrm{~cm}^{-1}\right)$, and (iv) multiple ion aggregates, $\left\{\mathrm{Li}^{+} \mathrm{ClO}_{4}^{-}\right\}_{n}(n \geq 2)\left(958 \mathrm{~cm}^{-1}\right)$. On the basis of this report, curve fitting was performed to separate each band. From the fitting results, the mole fraction of each species was obtained in a manner similar to the method used to obtain Table 1, and the results are shown in Table 2. Among the four kinds of $\mathrm{ClO}_{4}{ }^{-}$anions, three species were observed, except multiple ion aggregates, from $\mathrm{LiClO}_{4}$-PC solutions. It should be noted that an effective SEI formation and reversible lithium intercalation and deintercalation reactions took place in 3.8 and $4.7 \mathrm{~mol} \mathrm{dm}^{-3}$ solutions, in which contact ion pairs are present. In the other solutions, only free anions and solvent-separated ion pairs are present. These results suggest that the presence of contact ion pairs in the electrolyte enhances the SEI-forming ability. On the other hand, ion paring in $\mathrm{LiClO}_{4}-\mathrm{PC}$ solutions reduces the conductivity of the electrolyte. The maximum ionic conductivity is observed at $1.3 \mathrm{~mol} \mathrm{dm}^{-3} \mathrm{LiClO}_{4}-\mathrm{PC}$ solution [13]. At a higher concentration the conductivity decreases because of the higher viscosity originating from the formation of ion pairs in the solution. The conductivity appears to have little effect on SEI formation reactions. The detailed interpretation of the direct correlations between the conductivity and the SEI formation reactions is beyond the scope of the present work.

\section{Conclusions}

This study was conducted to better understand SEI formation reactions occurring at the interface between the graphite electrodes and PC-based electrolyte in lithium secondary batteries. Lithium ions were electrochemically intercalated into graphite in $\mathrm{LiClO}_{4}$ dissolved in PC by increasing the concentration of $\mathrm{LiClO}_{4}$. An effective SEI was formed on graphite in concentrated solutions without the aid of any SEI-forming agents. The results of this study suggest that the presence of contact ion pairs is an important factor that determines the SEI-forming ability in PC-based electrolytes. We are yet to understand the causative reasons for the SEI formation by contact ion pairs and intend to focus our future reports on gaining an understanding of the factors contributing to the electrolyte-concentration dependence of SEI formation in PC-based electrolytes.

\section{Conflict of Interests}

The authors declare that there is no conflict of interests regarding the publication of this paper.

\section{Acknowledgments}

This study was financially supported by the Small \& Medium Business Administration (no. S2136830). This work was supported by the Soonchunhyang University Research Fund. 


\section{References}

[1] R. Fong, U. von Sacken, and J. R. Dahn, "Studies of lithium intercalation into carbons using nonaqueous electrochemical cells," Journal of the Electrochemical Society, vol. 137, no. 7, pp. 2009-2013, 1990.

[2] Y. Ein-Eli, B. Markovsky, D. Aurbach, Y. Carmeli, H. Yamin, and S. Luski, "The dependence of the performance of Li$\mathrm{C}$ intercalation anodes for Li-ion secondary batteries on the electrolyte solution composition," Electrochimica Acta, vol. 39, no. 17 , pp. 2559-2569, 1994.

[3] J. T. Dudley, D. P. Wilkinson, G. Thomas et al., "Conductivity of electrolytes for rechargeable lithium batteries," Journal of Power Sources, vol. 35, no. 1, pp. 59-82, 1991.

[4] A. N. Dey and B. P. Sullivan, "The electrochemical decomposition of propylene carbonate on graphite," Journal of the Electrochemical Society, vol. 117, no. 2, pp. 222-224, 1970.

[5] J. O. Besenhard and H. P. Fritz, "Cathodic reduction of graphite in organic solutions of alkali and $\mathrm{NR}_{4}^{+}$salts," Journal of Electroanalytical Chemistry, vol. 53, no. 2, pp. 329-333, 1974.

[6] G. Eichinger, "Cathodic decomposition reactions of propylene carbonate," Journal of Electroanalytical Chemistry and Interfacial Electrochemistry, vol. 74, no. 2, pp. 183-193, 1976.

[7] S.-K. Jeong, M. Inaba, Y. Iriyama, T. Abe, and Z. Ogumi, "Interfacial reactions between graphite electrodes and propylene carbonate-based solutions: electrolyte-concentration dependence of electrochemical lithium intercalation reaction," Journal of Power Sources, vol. 175, no. 1, pp. 540-546, 2008.

[8] S.-K. Jeong, M. Inaba, R. Mogi, Y. Iriyama, T. Abe, and Z. Ogumi, "Surface film formation on a graphite negative electrode in lithium-ion batteries: atomic force microscopy study on the effects of film-forming additives in propylene carbonate solutions," Langmuir, vol. 17, no. 26, pp. 8281-8286, 2001.

[9] T. Ohzuku, Y. Iwakoshi, and K. Sawai, "Formation of lithiumgraphite intercalation compounds in nonaqueous electrolytes and their application as a negative electrode for a lithium ion (shuttlecock) cell," Journal of the Electrochemical Society, vol. 140, no. 9, pp. 2490-2497, 1993.

[10] J. R. Dahn, "Phase diagram of $\mathrm{Li}_{x} \mathrm{C}_{6}$ " Physical Review B, vol. 44, no. 17, pp. 9170-9177, 1991.

[11] A. Funabiki, M. Inaba, T. Abe, and Z. Ogumi, "Influence of defects on the phase-boundary movement in a stage transformation of lithium-graphite intercalation compounds," Carbon, vol. 37, no. 10, pp. 1591-1598, 1999.

[12] M. Inaba, Z. Siroma, Y. Kawatate, A. Funabiki, and Z. Ogumi, "Electrochemical scanning tunneling microscopy analysis of the surface reactions on graphite basal plane in ethylene carbonate-based solvents and propylene carbonate," Journal of Power Sources, vol. 68, no. 2, pp. 221-226, 1997.

[13] D. Battisti, G. A. Nazri, B. Klassen, and R. Aroca, "Vibrational studies of lithium perchlorate in propylene carbonate solutions," The Journal of Physical Chemistry, vol. 97, no. 22, pp. 5826-5830, 1993.

[14] K. Kondo, M. Sano, A. Hiwara et al., "Conductivity and solvation of $\mathrm{Li}^{+}$ions of $\mathrm{LiPF}_{6}$ in propylene carbonate solutions," The Journal of Physical Chemistry B, vol. 104, no. 20, pp. 50405044, 2000.

[15] Z. Wang, W. Gao, X. Huang, Y. Mo, and L. Chen, "Spectroscopic studies on interactions and microstructures in propylene carbonate-LiTFSI electrolytes," Journal of Raman Spectroscopy, vol. 32, no. 11, pp. 900-905, 2001.
[16] W. Huang and R. Frech, "In situ Raman studies of graphite surface structures during lithium electrochemical intercalation," Journal of the Electrochemical Society, vol. 145, no. 3, pp. 765770, 1998.

[17] L. J. Hardwick, H. Buqa, M. Holzapfel, W. Scheifele, F. Krumeich, and P. Novák, "Behaviour of highly crystalline graphitic materials in lithium-ion cells with propylene carbonate containing electrolytes: an in situ Raman and SEM study, Electrochimica Acta, vol. 52, no. 15, pp. 4884-4891, 2007.

[18] D. W. James and R. E. Mayers, "Ion-ion-solvent interactions in solution. I. Solutions of $\mathrm{LiClO}_{4}$ in acetone," Australian Journal of Chemistry, vol. 35, no. 9, pp. 1775-1784, 1982. 

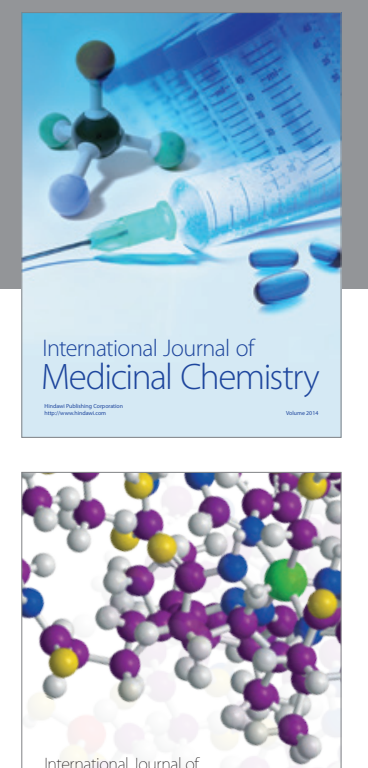

\section{Carbohydrate} Chemistry

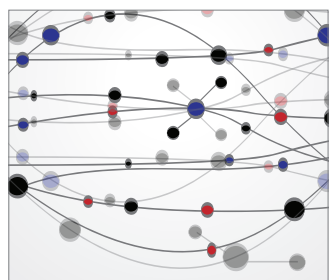

The Scientific World Journal
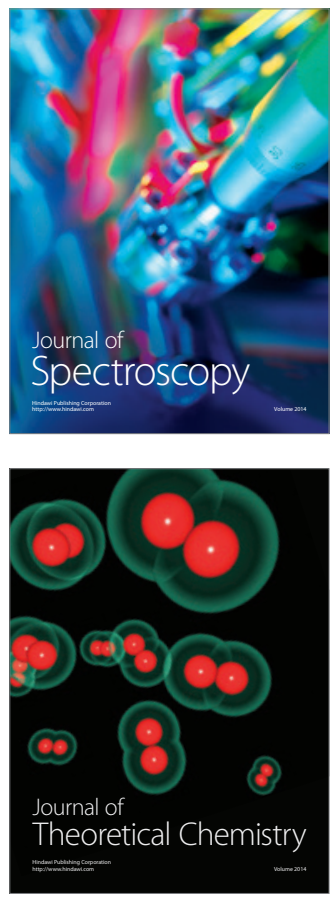
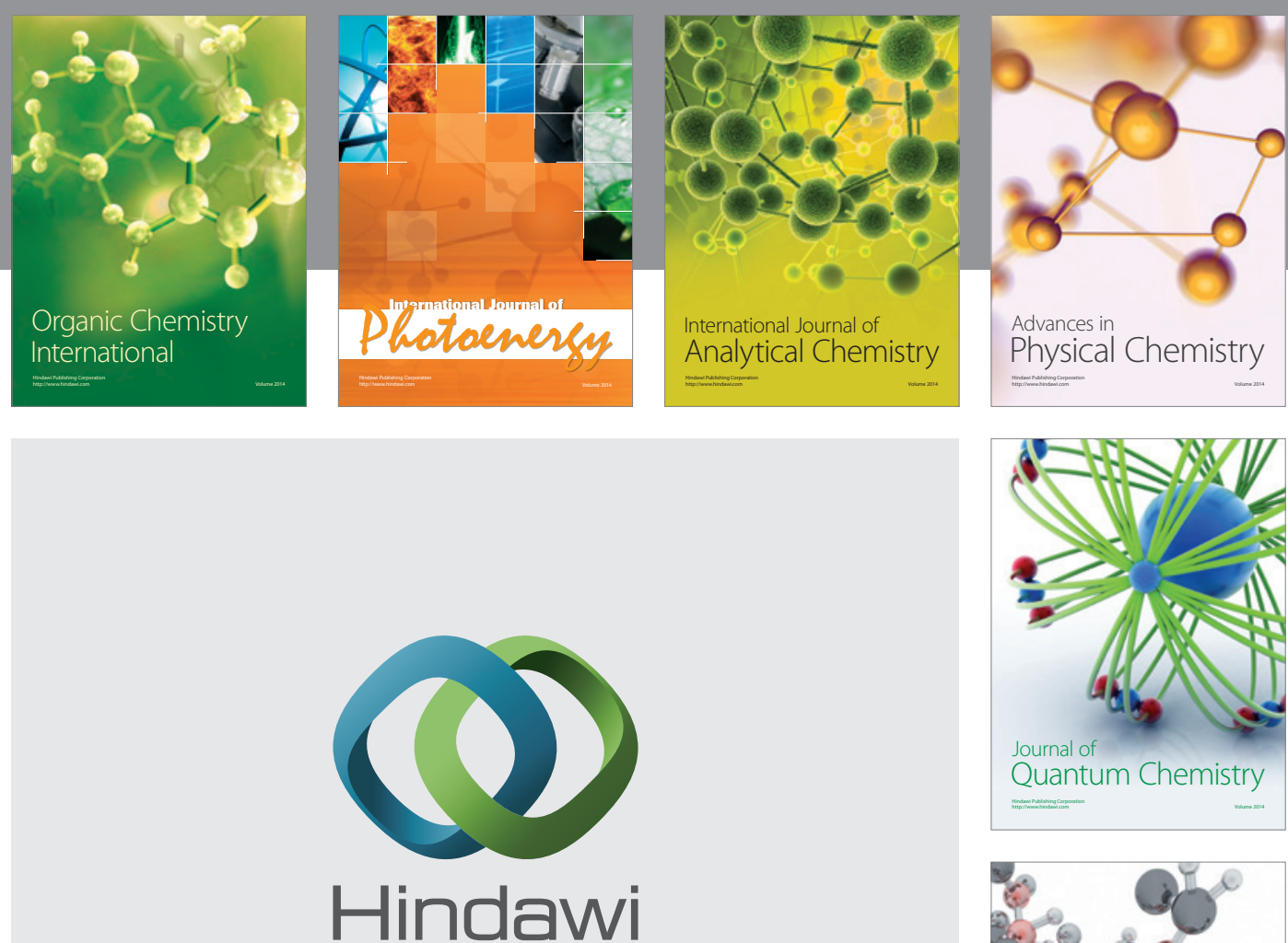

Submit your manuscripts at

http://www.hindawi.com

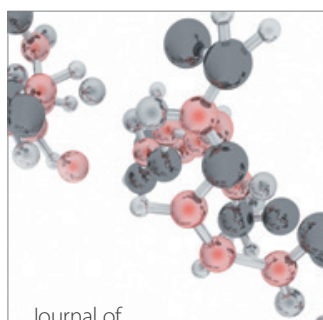

Analytical Methods

in Chemistry

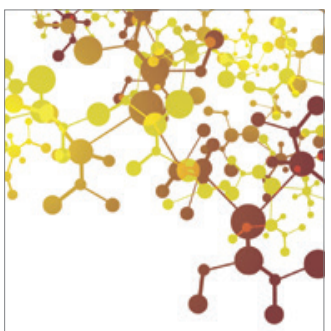

Journal of

Applied Chemistry

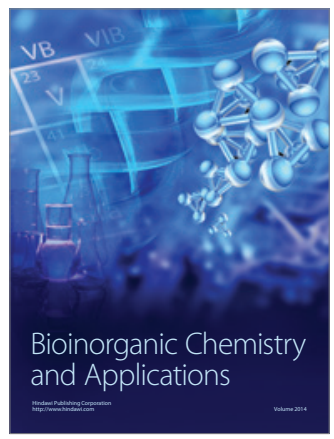

Inorganic Chemistry
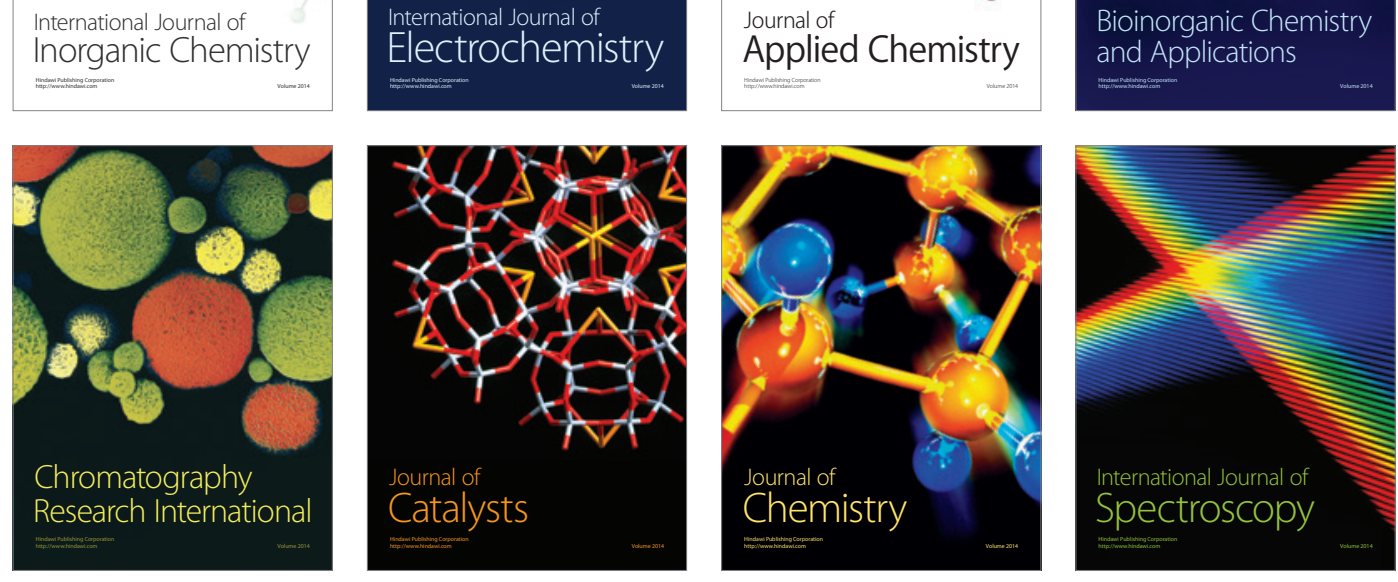